\title{
Welcome and farewell
}

\author{
Lesley Rees ${ }^{1}$ (D) $\cdot$ Michel Baum ${ }^{2} \cdot$ Joseph Flynn ${ }^{3,4}$
}

Received: 19 November 2020 / Accepted: 19 November 2020 / Published online: 21 December 2020

(C) IPNA 2020

Dear Friends and Colleagues,

This has been a turbulent year for us all, and for the journal, the year ends with Prof Michel Baum's departure after 15 years at its helm. He joined Otto Mehls as coeditor of the journal in 2005, taking over from Russell Chesney. During his tenure, Michel has overseen the implementation of several key innovations, including electronic submission and review systems, and the development of new article types, all of which have been instrumental in the journal accomplishing an impressive gain in Impact Factor from 1.62 to 2.68 today, and which have helped the journal stand out in an increasingly crowded market. He will be greatly missed. His replacement is Joseph Flynn, who was appointed as co-editor by IPNA council in June and will start in 2021. We wish Michel and Joseph all the very best.

Despite the pandemic that has changed all our ways of life, we have seen submissions increase by nearly $40 \%$ ! We would like to especially thank the journal staff and Springer, but in particular we would like to thank our contributors and reviewers for the extra work that has been needed to support this increase.

We will continue to provide our readers with the latest scientific developments in pediatric nephrology, including invited reviews and editorial commentaries, as well as original research from the pediatric nephrology community. Our editorial team is committed to continuous innovation, including

Lesley Rees

1.rees@ucl.ac.uk

1 Pediatric Nephrology, UCL Great Ormond Street Institute of Child Health, UCL, London, UK

2 UTSouthwestern Medical Center, Dallas, TX, USA

3 Division of Nephrology, Seattle Children's Hospital, 4800 Sand Point Way NE, Seattle, WA 98105, USA

4 Department of Pediatrics, University of Washington School of Medicine, Seattle, WA, USA growing our online presence and visibility through social media, and introduction of new features such as Graphical Abstracts.

Please let us know if you have suggestions for improvement, or ideas for review topics. And as always, please send us your best work.

We would like to thank all IPNA members and readers who also contribute to the success of the journal and wish you all health and happiness for 2021.

Seasons Greetings,

Lesley, Joseph and Michel.

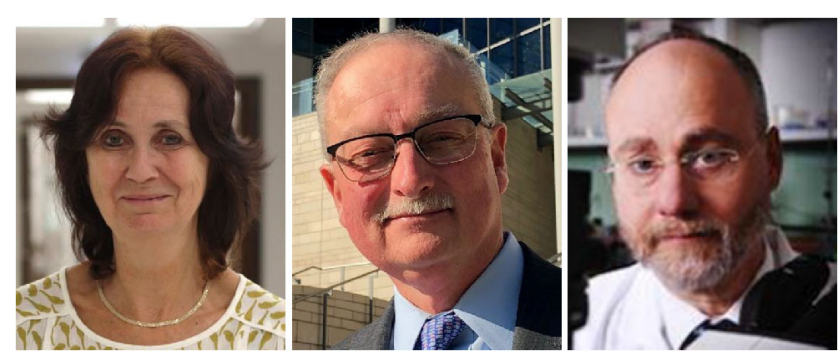

Publisher's note Springer Nature remains neutral with regard to jurisdictional claims in published maps and institutional affiliations. 